\title{
Correction: Blood transcriptional profiling reveals IL-1 and integrin signaling pathways associated with clinical response to extracorporeal photopheresis in patients with leukemic cutaneous T-cell lymphoma
}

\section{Zuolin Ying ${ }^{1}$, Lisa Shiue ${ }^{1}$, Katherine Park ${ }^{1}$, Jutta Kollet ${ }^{2}$, Pedram Bijani ${ }^{1}$, Meghali Goswami ${ }^{1}$, Madeleine Duvic ${ }^{1}$ and $\mathrm{Xiao} \mathbf{N i}^{1}$}

${ }^{1}$ Department of Dermatology, The University of Texas MD Anderson Cancer Center, Houston, TX 77030, USA

${ }^{2}$ Bioinformatics, Miltenyi Biotec GmbH, Bergisch Gladbach, 51429, Germany

Published: September 10, 2019

Copyright: Ying et al. This is an open-access article distributed under the terms of the Creative Commons Attribution License 3.0 (CC BY 3.0), which permits unrestricted use, distribution, and reproduction in any medium, provided the original author and source are credited.

This article has been corrected: The \#2 affiliation information has been updated. The proper institution name is shown below:

\footnotetext{
${ }^{2}$ Bioinformatics, Miltenyi Biotec GmbH, Bergisch Gladbach, 51429, Germany

Original article: Oncotarget. 2019; 10:3183-3197. https://doi.org/10.18632/oncotarget.26900
} 